\title{
Salivary Cortisol Determination in ACTH Stimulation Test to Diagnose Adrenal Insufficiency in Patients with Liver Cirrhosis
}

\author{
Lara Albert $\mathbb{D}^{1},{ }^{1}$ Joaquím Profitós, ${ }^{2}$ Jordi Sánchez-Delgado $\mathbb{D},{ }^{2,3}$ Ismael Capel $\mathbb{D},{ }^{1}$ \\ José Miguel González-Clemente, ${ }^{1}$ David Subías, ${ }^{1}$ Albert Cano ${ }^{D},{ }^{1}$ Eugenio Berlanga, ${ }^{4}$ \\ Anna Espinal, ${ }^{5}$ Marta Hurtado, ${ }^{1}$ Rocío Pareja, ${ }^{1}$ Mercedes Rigla $\left(\mathbb{D},{ }^{1}\right.$ Blai Dalmau, ${ }^{2}$ \\ Mercedes Vergara, ${ }^{2,3}$ Mireia Miquel, ${ }^{2,3}$ Meritxell Casas, ${ }^{2}$ and Olga Giménez-Palop ${ }^{1}$ \\ ${ }^{1}$ Endocrinology Department, Parc Taulí University Hospital, Institut d’Investigacio i Innovació Parc Taulí I3PT, \\ Autonomous University of Barcelona, Sabadell, Spain \\ ${ }^{2}$ Liver and Gastrointestinal Diseases Department, Parc Tauli University Hospital, Institut d'Investigacio i Innovació Parc Taulí I3PT, \\ Autonomous University of Barcelona, Sabadell, Spain \\ ${ }^{3}$ Centro de Investigación Biomédica en Red de Enfermedades Hepáticas y Digestivas (CIBERehd), Instituto de Salud Carlos III, Spain \\ ${ }^{4}$ Clinical Laboratory Department, Institut d'Investigació i Innovació Parc Taulí I3PT, Parc Taulí University Hospital, \\ Autonomous University of Barcelona, Sabadell, Spain \\ ${ }^{5}$ Servei d'Estadística Aplicada, Universitat Autònoma de Barcelona, Bellaterra, Spain
}

Correspondence should be addressed to Jordi Sánchez-Delgado; jsanchezd@tauli.cat

Received 14 March 2019; Revised 13 May 2019; Accepted 19 May 2019; Published 20 June 2019

Academic Editor: Giuseppe Reimondo

Copyright (c) 2019 Lara Albert et al. This is an open access article distributed under the Creative Commons Attribution License, which permits unrestricted use, distribution, and reproduction in any medium, provided the original work is properly cited.

Purpose. The prevalence of adrenal insufficiency (AI) in patients with decompensated liver cirrhosis is unknown. Because these patients have lower levels of cortisol-binding carrier proteins, their total serum cortisol (TSC) correlates poorly with free serum cortisol (FC). Salivary cortisol $(\mathrm{SaC})$ correlates better with FC. We aimed to establish SaC thresholds for AI for the $250 \mu \mathrm{g}$ intravenous ACTH test and to estimate the prevalence of AI in noncritically ill cirrhotic patients. Methods. We included 39 patients with decompensated cirrhosis, 39 patients with known AI, and 45 healthy volunteers. After subjects fasted $\geq 8$ hours, serum and saliva samples were collected for determinations of TSC and SaC at baseline $0^{\prime}\left(\mathrm{T}_{0}\right)$ and at 30-minute intervals after intravenous administration of $250 \mu \mathrm{g}$ ACTH [30' $\left(\mathrm{T}_{30}\right), 60^{\prime}\left(\mathrm{T}_{60}\right)$, and $\left.90^{\prime}\left(\mathrm{T}_{90}\right)\right]$. Results. Based on the findings in healthy subjects and patients with known AI, we defined AI in cirrhotic patients as SaC- $\mathrm{T}_{0}<0.08 \mu \mathrm{g} / \mathrm{dL}(2.2 \mathrm{nmol} / \mathrm{L}), \mathrm{SaC} \mathrm{T}_{60}<1.43 \mu \mathrm{g} / \mathrm{dl}(39.5 \mathrm{nmol} / \mathrm{L})$, or $\Delta \mathrm{SaC}<1 \mu \mathrm{g} / \mathrm{dl}(27.6 \mathrm{nmol} / \mathrm{L})$. We compared AI determination in cirrhotic patients with the ACTH test using these SaC thresholds versus established TSC thresholds (TSC-T ${ }_{0}<9 \mu \mathrm{g} / \mathrm{dl}[248 \mathrm{nmol} / \mathrm{L}]$, TSC-T ${ }_{60}<18 \mu \mathrm{g} / \mathrm{dl}[497 \mathrm{nmol} / \mathrm{L}]$, or $\Delta \mathrm{TSC}<9 \mu \mathrm{g} / \mathrm{dl}[248$ $\mathrm{nmol} / \mathrm{L}])$. SaC correlated well with TSC. The prevalence of AI in cirrhotic patients was higher when determined by TSC (48.7\%) than by $\mathrm{SaC}$ (30.8\%); however, this difference did not reach statistical significance. AI was associated with sex, cirrhosis etiology, and Child-Pugh classification. Conclusions. Measuring SaC was more accurate than TSC in the ACTH stimulation test. Measuring TSC overestimated the prevalence of AI in noncritically ill cirrhotic patients.

\section{Introduction}

Adrenal insufficiency (AI) is common in patients with liver disease; AI is present in both patients with severe cirrhosis admitted to intensive care units and stable patients [1-3]. Relative AI in patients with cirrhosis is a sum of primary (lack of steroid precursors, such as cholesterol) and secondary (impairment of CRH-ACTH axis) AI. The lack of specific symptoms of acute and chronic AI makes the diagnosis difficult.

The insulin tolerance test is considered the gold standard for evaluating the hypothalamus-pituitary-adrenal axis. However, in clinical practice, the short ACTH stimulation test is more widely used because it is better tolerated and has fewer contraindications. Both tests are based on the analysis of serum cortisol, and the correlation between the two is well 
studied; most clinical guidelines support the use of the ACTH test for diagnosing AI $[4,5]$.

Serum cortisol is mostly bound to carrier proteins such as cortisol-binding globulin (CBG) and albumin [6]. Free cortisol (FC), the biologically active unbound fraction, represents about $5 \%$ to $10 \%$ of total serum cortisol (TSC) [7, 8]. Various conditions affect protein synthesis. For instance, cirrhosis, malnutrition, and critical illness reduce it, whereas oral contraceptives and pregnancy increase it. Thus, TSC does not accurately reflect FC, increasing the risk of misdiagnosis [9-11]. Rauschecker et al. [12] recently demonstrated that measuring FC in response to ACTH stimulation is a good alternative to TSC for diagnosing AI. However, FC analysis is time-consuming and expensive, hindering its use for routine laboratory testing. The FC fraction can be calculated using the Coolens' equation, but the results are unsatisfactory [13]. An easier, less expensive approach is to determine FC indirectly by measuring salivary cortisol $(\mathrm{SaC})$, a surrogate of plasma FC [14].

Late-night (23:00-24:00 h) SaC is widely used to detect hypercortisolism when Cushing's syndrome is suspected [15]. Various authors have proposed using SaC instead of TSC after ACTH stimulation tests [15-17], but limited data are available to validate this approach.

We aimed to determine the reference values for $\mathrm{SaC}$ after stimulation with $250 \mu \mathrm{g}$ intravenous $\mathrm{ACTH}$, to determine the diagnostic accuracy of these values for AI in noncritical patients with cirrhosis, and to estimate the prevalence of AI in this population.

\section{Materials and Methods}

Subjects were enrolled from April 2013 through October 2015. We included (a) 45 healthy adults recruited from hospital staff (17 men; mean age, 30 years; range, 22-49 years); none required medication within 1 month of testing, and all had normal liver, renal, and thyroid function; (b) 41 endocrinology patients with known AI diagnosed by insulin tolerance test or short $250 \mu \mathrm{g}$ ACTH test (12 men; mean age, 57 years; range, 24-86 years; 13 primary AI, 26 secondary AI); and (c) 39 noncritical cirrhotic patients hospitalized for cirrhosis-related complications ( 34 men; mean age, 58 years; range, 39-90 years). Cirrhosis was diagnosed through histological or clinical, biological, and ultrasonographic findings. Table 1 reports cirrhotic patients' demographic and clinical data. Reasons for hospitalization were ascites, gastrointestinal bleeding, infection without systemic inflammatory response syndrome, alcoholic hepatitis, acute kidney injury, and others.

Exclusion criteria were age $<18$ years; pregnancy; use of glucocorticoids (except in AI patients) or oral contraceptives $<6$ months before inclusion; severe acute illness; mean arterial pressure < $60 \mathrm{mmHg}$; blood in the mouth; administration of albumin, fresh frozen plasma, or terlipressin before inclusion; or absence of consent.

At inclusion, patients were examined, with special attention to the presence of blood in the mouth. Patients were told not to brush their teeth, smoke, or drink anything but water during the $60 \mathrm{~min}$ before sampling. Patients on chronic
TABLE 1: Clinical characteristics of cirrhotic patients.

\begin{tabular}{|c|c|}
\hline Variable & Data \\
\hline Age, years* & $58.5 \pm 11.7$ \\
\hline Age at diagnosis of cirrhosis, years* & $53.8 \pm 10.8$ \\
\hline Male sex, n (\%) & $34(87.2)$ \\
\hline \multicolumn{2}{|l|}{ Cirrhosis etiology, n (\%) } \\
\hline Alcohol & $30(76.9)$ \\
\hline Alcohol and HCV & $5(12.8)$ \\
\hline Alcohol and HBV & $2(5.1)$ \\
\hline Primary biliary cirrhosis & $1(2.6)$ \\
\hline Autoimmune disorder & $1(2.6)$ \\
\hline Type 2 diabetes, n (\%) & $9(23)$ \\
\hline Ascites/edema, n (\%) & $35(89.7)$ \\
\hline Encephalopathy, n (\%) & $9(23.1)$ \\
\hline Hypertension, n (\%) & $12(30.8)$ \\
\hline Child-Pugh score $*$ & $9 \pm 2$ \\
\hline Class A/B/C, n (\%) & $6(15.4) / 18(46.2) / 15(38.5)$ \\
\hline MELD score* & $17 \pm 6$ \\
\hline Albumin, $g / L *$ & $30.4 \pm 6.4$ \\
\hline Prealbumin, g/L* & $6.0 \pm 2.4$ \\
\hline Cholesterol, $\mathrm{mg} / \mathrm{dL}^{\delta}$ & $109(83-134)$ \\
\hline HDL cholesterol, $\mathrm{mg} / \mathrm{dL}^{\delta}$ & $28(13-39)$ \\
\hline LDL cholesterol, $\mathrm{mg} / \mathrm{dL}^{\delta}$ & $68(50-78)$ \\
\hline Triglycerides, $\mathrm{mg} / \mathrm{dL}^{\delta}$ & $72(56-105)$ \\
\hline AST, IU/L ${ }^{\delta}$ & $47(34-61)$ \\
\hline $\mathrm{ALT}, \mathrm{IU} / \mathrm{L}^{\delta}$ & $21(15-31)$ \\
\hline GGT, IU/L ${ }^{\delta}$ & $108(39-225)$ \\
\hline Bilirubin, $\mathrm{mg} / \mathrm{dL}^{\delta}$ & $2.6(1.6-5.8)$ \\
\hline Prothrombin time $*$ & $1.68 \pm 0.91$ \\
\hline INR* & $1.80 \pm 0.98$ \\
\hline
\end{tabular}

* Mean $\pm \mathrm{SD}{ }^{\delta}$ median $(\mathrm{Q} 1-\mathrm{Q} 3)$.

corticosteroid replacement therapy received their last dose at 9:00 a.m. the day before testing.

The first sample was extracted between 8:30 a.m. and 9:30 a.m. after at least $8 \mathrm{~h}$ fasting. To avoid stress-induced bias, baseline $\left(\mathrm{T}_{0}\right)$ samples were obtained 30 minutes after catheterization of a superficial vein. Blood samples were drawn from the catheter. Saliva samples were collected after patients chewed a cotton swab specially designed for cortisol determination from saliva (Salivette ${ }^{\circledR}$, Sarstedt AG\&Co; Nümbrecht, Germany) for 1 to 3 minutes. After $250 \mu \mathrm{g}$ of synthetic ACTH (Synacthen ${ }^{\circledR}$, Alfasigma; Milan, Italy) was administered intravenously, blood and saliva samples were collected at minutes $30\left(\mathrm{~T}_{30}\right), 60\left(\mathrm{~T}_{60}\right)$, and $90\left(\mathrm{~T}_{90}\right)$. All samples were processed immediately.

$\mathrm{SaC}$ and TSC levels were determined by electrochemiluminescence assay (Roche Diagnostics GmbH; Mannheim, Germany) [lower limit of detection, $0.018 \mu \mathrm{g} / \mathrm{dL}(0.50$ $\mathrm{nmol} / \mathrm{L}$ ); coefficient of variation, $4.1 \%-4.9 \%$ at high levels and $7.5 \%-11.5 \%$ at low levels]. Values of $\mathrm{SaC}$ or TSC $<0.018 \mu \mathrm{g} / \mathrm{dL}$ $(0.50 \mathrm{nmol} / \mathrm{L})$ were excluded from the analyses.

For the diagnosis of AI, we used the following established cutoffs: TSC $\mathrm{T}_{0}<9 \mu \mathrm{g} / \mathrm{dl}(248 \mathrm{nmol} / \mathrm{L})$, TSC $\mathrm{T}_{60}<18$ 
TABLE 2: Serum cortisol concentrations in healthy volunteers, adrenal insufficient patients, and cirrhotic patients in the $250 \mu \mathrm{g}$ ACTH test.

\begin{tabular}{|c|c|c|c|c|c|c|c|c|}
\hline & & \multicolumn{7}{|c|}{ Serum cortisol $(\mu \mathrm{g} / \mathrm{dL})$} \\
\hline & & Mean & Median & $\mathrm{SD}$ & Min & Q1 & Q3 & Max \\
\hline \multicolumn{9}{|l|}{ Group } \\
\hline \multirow{4}{*}{ Healthy } & $\mathrm{T}_{0}$ & 15.15 & 13.95 & 5.66 & 6.14 & 11.18 & 18.48 & 29.61 \\
\hline & $\mathrm{T}_{30}$ & 26.45 & 27.34 & 4.64 & 18.74 & 23.15 & 29.63 & 41.26 \\
\hline & $\mathrm{T}_{60}$ & 31.12 & 32.23 & 4.60 & 22.09 & 27.38 & 34.01 & 45.24 \\
\hline & $\mathrm{T}_{90}$ & 34.22 & 34.55 & 4.72 & 26.29 & 30.62 & 37.68 & 47.68 \\
\hline \multirow{4}{*}{ Adrenal insufficiency } & $\mathrm{T}_{0}$ & 1.94 & 0.67 & 2.78 & 0.03 & 0.21 & 2.45 & 10.10 \\
\hline & $\mathrm{T}_{30}$ & 3.87 & 2.23 & 4.61 & 0.03 & 0.68 & 5.07 & 17.53 \\
\hline & $\mathrm{T}_{60}$ & 4.78 & 2.51 & 5.52 & 0.03 & 0.84 & 6.42 & 21.20 \\
\hline & $\mathrm{T}_{90}$ & 5.22 & 2.54 & 6.14 & 0.03 & 0.84 & 7.09 & 23.30 \\
\hline \multirow{4}{*}{ Cirrhosis } & $\mathrm{T}_{0}$ & 12.75 & 12.27 & 5.91 & 2.05 & 8.20 & 17.80 & 24.85 \\
\hline & $\mathrm{T}_{30}$ & 21.52 & 22.35 & 6.79 & 11.02 & 16.35 & 26.33 & 40.20 \\
\hline & $\mathrm{T}_{60}$ & 26.23 & 26.73 & 7.93 & 13.83 & 18.59 & 32.96 & 42.76 \\
\hline & $\mathrm{T}_{90}$ & 29.94 & 29.89 & 9.01 & 15.28 & 21.31 & 38.17 & 45.67 \\
\hline
\end{tabular}

$\mathrm{T}_{0}$, baseline; $\mathrm{T}_{30}, 30 \mathrm{~min}$ after administration; $\mathrm{T}_{60}, 60 \mathrm{~min}$ after administration; $\mathrm{T}_{90}, 90 \mathrm{~min}$ after administration. To convert cortisol micrograms per deciliter to nanomoles per liter, multiply by 27.6 .

TABLE 3: Change in serum cortisol between baseline and 60 minutes in healthy volunteers, adrenal insufficient patients, and cirrhotic patients in the $250 \mu \mathrm{g}$ ACTH test.

\begin{tabular}{|c|c|c|c|c|c|c|c|}
\hline & \multicolumn{7}{|c|}{ Delta serum cortisol $(\mu \mathrm{g} / \mathrm{dL})$} \\
\hline & Mean & Median & Std & Min & Q1 & Q3 & Max \\
\hline \multicolumn{8}{|l|}{ Group } \\
\hline Healthy & 15.97 & 15.63 & 4.80 & 7.31 & 12.30 & 19.63 & 25.34 \\
\hline Adrenal insufficiency & 2.83 & 1.73 & 3.14 & -0.04 & 0.19 & 5.17 & 12.33 \\
\hline Cirrhosis & 13.48 & 13.06 & 5.36 & 4.23 & 8.70 & 16.51 & 25.56 \\
\hline
\end{tabular}

To convert cortisol micrograms per deciliter to nanomoles per liter, multiply by 27.6 .

$\mu \mathrm{g} / \mathrm{dl}(497 \mathrm{nmol} / \mathrm{L})$, or $\Delta \mathrm{TSC}$ (increase between $\mathrm{T}_{0}$ and $\mathrm{T}_{60}$ ) $<9 \mu \mathrm{g} / \mathrm{dl}(248 \mathrm{nmol} / \mathrm{L})$ [4, 18-20]. Salivary cortisol cutoffs were defined as the minimum $\mathrm{SaC}$ concentration observed in healthy subjects at $\mathrm{T}_{0}$ and $\mathrm{T}_{60}$ and the minimum $\Delta \mathrm{SaC}$ value. We analyzed the correlation between TSC levels and $\mathrm{SaC}$ levels. We used the SaC cutoffs and TSC cutoffs to assess the prevalence of $\mathrm{AI}$ in the cirrhotic group and compared the results obtained with the two methods.

We did a descriptive analysis of patients' clinical characteristics. We used descriptive statistics to summarize the values of TSC and $\mathrm{SaC}$ at each timepoint and the differences between their values at baseline and 60 minutes ( $\triangle$ TSC and $\Delta \mathrm{SaC}$ ). Using these statistics, we defined three criteria for the diagnosis of AI. The likelihood-ratio test was used to check the goodness of fit.

We used SAS 9.3 (SAS System, Cary, NC, USA, 2013) for all analyses.

\section{Results}

3.1. Healthy and AI Subjects. All healthy controls had TSC $\geq 18$ $\mu \mathrm{g} / \mathrm{dL}(497 \mathrm{nmol} / \mathrm{L})$ at $\mathrm{T}_{60}$; two AI subjects surpassed this cutoff and were excluded from the analyses. Figure 1 shows the distribution of TSC and SaC after ACTH stimulation. As expected, all TSC determinations were lower in AI subjects than in healthy subjects (Table 2). Mean $\Delta$ TSC was $15.97 \pm 4.80$ $\mu \mathrm{g} / \mathrm{dL}(441 \pm 132 \mathrm{nmol} / \mathrm{L})$ in healthy subjects and $2.84 \pm 3.14$ $\mu \mathrm{g} / \mathrm{dL}(78 \pm 87 \mathrm{nmol} / \mathrm{L})$ in AI patients (Table 3).

In healthy subjects, mean $\mathrm{SaC}$ at $\mathrm{T}_{0}$ was $0.56 \pm 0.31 \mu \mathrm{g} / \mathrm{dL}$ $(15 \pm 9 \mathrm{nmol} / \mathrm{L})$; the lowest value was $0.08 \mu \mathrm{g} / \mathrm{dL}(2.2 \mathrm{nmol} / \mathrm{L})$ (Table 4). The area under the receiver operating characteristic curve for $\mathrm{SaC}_{-} \mathrm{T}_{0}$ was 0.8045 . After ACTH stimulation, $\mathrm{SaC}$ progressively increased in nearly all healthy subjects; the lower limit of $\mathrm{SaC}$ at $\mathrm{T}_{60}$ was $1.43 \mu \mathrm{g} / \mathrm{dL}(39.5 \mathrm{nmol} / \mathrm{L})$ (Table 4$)$. The cutoff $\mathrm{SaC}$ at $\mathrm{T}_{60}>1.43 \mu \mathrm{g} / \mathrm{dL}(39.5 \mathrm{nmol} / \mathrm{L})$ classified all AI patients correctly.

In healthy subjects, mean $\Delta \mathrm{SaC}$ was $1.79 \pm 0.59 \mu \mathrm{g} / \mathrm{dL}$ $(49.4 \pm 16.3 \mathrm{nmol} / \mathrm{L})$; the lowest value was $1 \mu \mathrm{g} / \mathrm{dL}(27.6$ nmol/L) (Table 5). We defined these concentrations (SaC$\mathrm{T}_{0}<0.08 \mu \mathrm{g} / \mathrm{dL}[2.2 \mathrm{nmol} / \mathrm{L}], \mathrm{SaC} \mathrm{T}_{60}<1.43 \mu \mathrm{g} / \mathrm{dL}[39.5$ $\mathrm{nmol} / \mathrm{L}], \Delta \mathrm{SaC}<1 \mu \mathrm{g} / \mathrm{dL}[27.6 \mathrm{nmol} / \mathrm{L}])$ as cutoff values for the diagnosis of $\mathrm{AI}$.

In $\mathrm{AI}$ patients, mean $\mathrm{SaC}$ at $\mathrm{T}_{0}$ was $0.33 \pm 0.30 \mu \mathrm{g} / \mathrm{dL}$ $(9.1 \pm 8.3 \mathrm{nmol} / \mathrm{L})$; the highest value was $1.53 \mu \mathrm{g} / \mathrm{dL}(42.2$ $\mathrm{nmol} / \mathrm{L}$ ) (Table 4). After ACTH stimulation, $\mathrm{SaC}$ in AI patients mainly remained constant over time (Table 4). The highest concentration of $\mathrm{SaC}$ at $\mathrm{T}_{60}$ in $\mathrm{AI}$ patients was $0.90 \mu \mathrm{g} / \mathrm{dL}(24.8 \mathrm{nmol} / \mathrm{L})$; therefore, the SaC- $\mathrm{T}_{60}$ cutoff classified all AI patients correctly. Mean $\Delta \mathrm{SaC}$ in AI patients was $-0.004 \pm 0.18 \mu \mathrm{g} / \mathrm{dL}(-0.11 \pm 5.0 \mathrm{nmol} / \mathrm{L})$; all had $\Delta \mathrm{SaC}$ values lower than $1 \mu \mathrm{g} / \mathrm{dL}(27.6 \mathrm{nmol} / \mathrm{L})$ (Table 5). 
TABLE 4: Salivary cortisol concentrations in healthy volunteers, adrenal insufficient patients, and cirrhotic patients in the $250 \mu \mathrm{g}$ ACTH test.

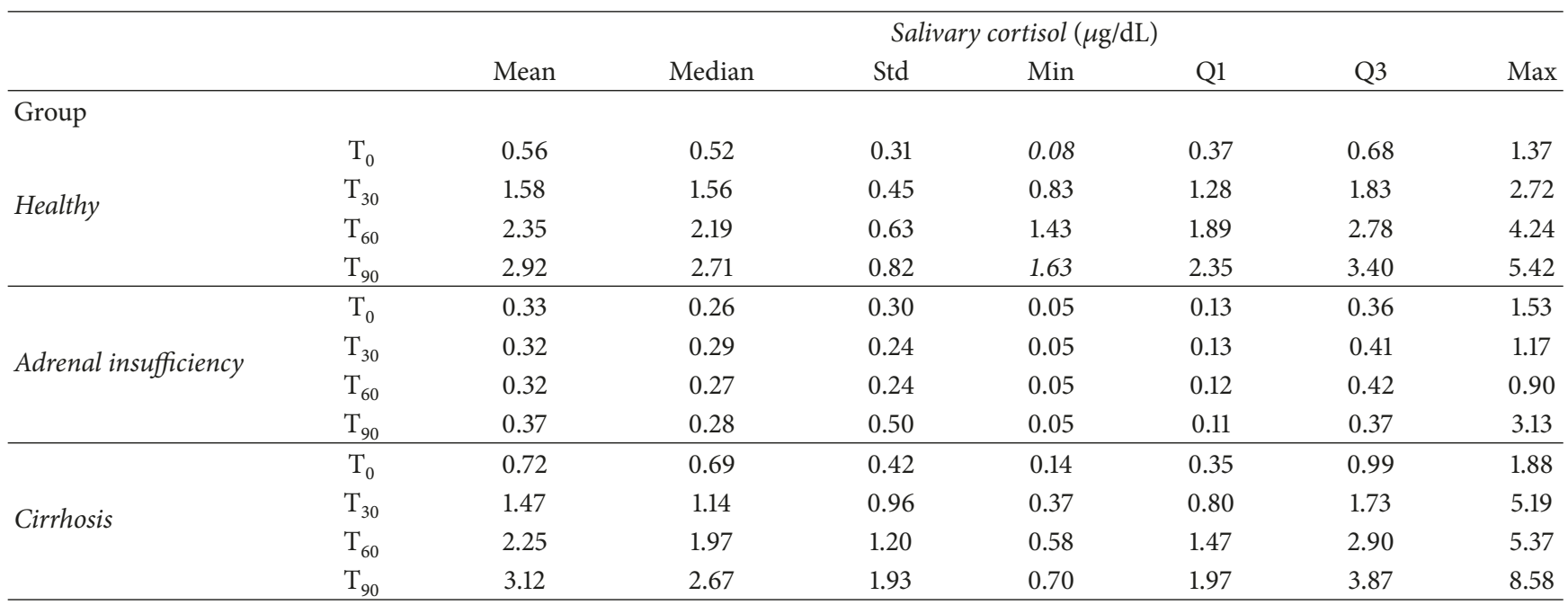

To convert cortisol micrograms per deciliter to nanomoles per liter, multiply by 27.6 .

TABLE 5: Change in salivary cortisol between baseline and 60 minutes in healthy volunteers, adrenal insufficient patients, and cirrhotic patients in the $250 \mu \mathrm{g}$ ACTH test.

\begin{tabular}{lccccrrr}
\hline & \multicolumn{9}{c}{ Delta salivary cortisol $(\mu \mathrm{g} / \mathrm{dL})$} \\
& Mean & Median & Std & Min & Q1 & Q3 & Max \\
\hline Group & & & & & \\
Healthy & 1.79 & 1.67 & 0.59 & 0.99 & 1.38 & 2.03 \\
Adrenal insufficiency & -0.00 & 0.00 & 0.18 & -0.72 & -0.02 & 0.06 \\
Cirrhosis & 1.53 & 1.33 & 0.99 & 0.08 & 0.80 & 1.98 \\
\hline
\end{tabular}

To convert cortisol micrograms per deciliter to nanomoles per liter, multiply by 27.6 .
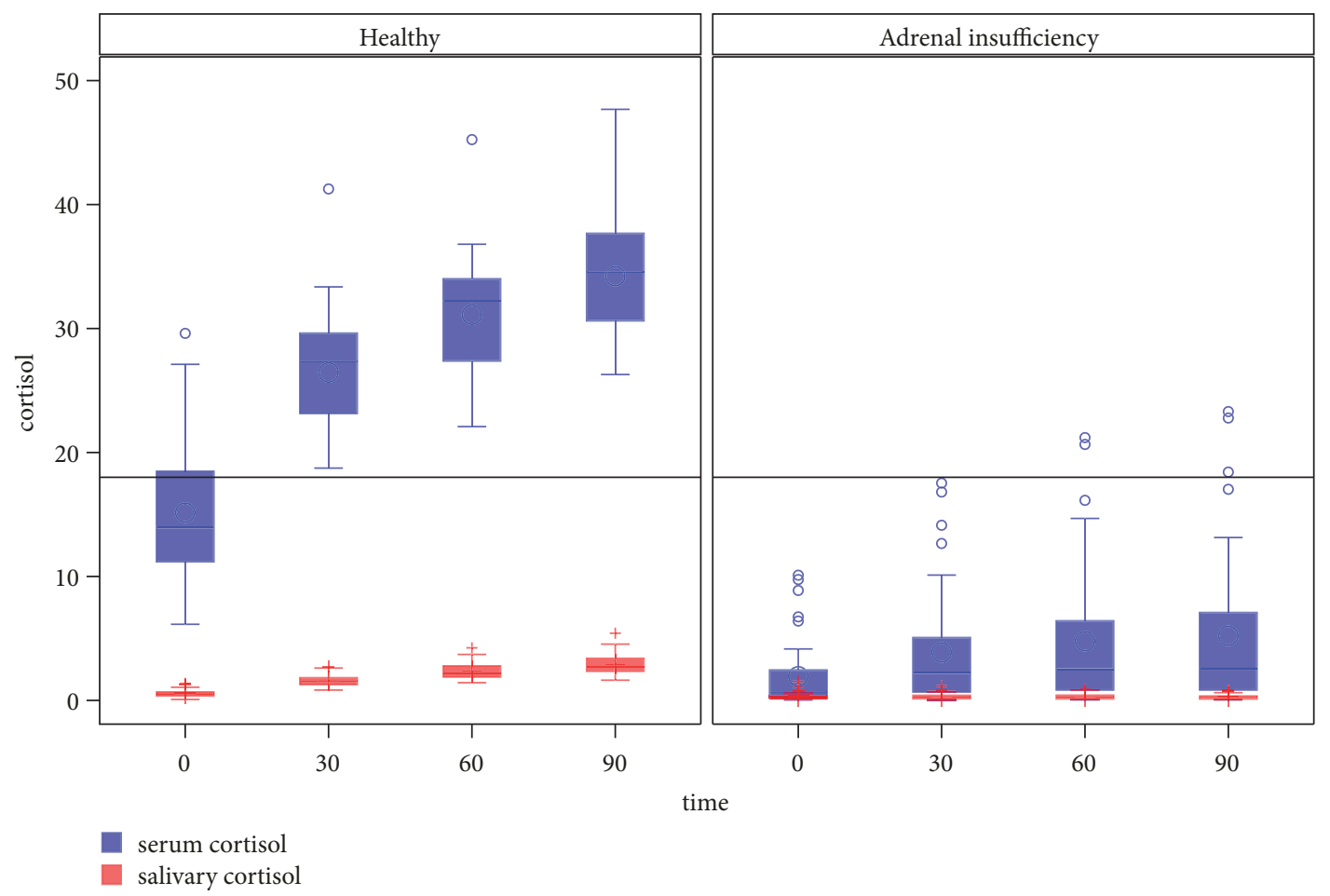

FIGURE 1: Serum and salivary cortisol $(\mu \mathrm{g} / \mathrm{dL})$ in the $250 \mu \mathrm{g}$ ACTH test. To convert cortisol micrograms per deciliter to nanomoles per liter, multiply by 27.6 . 
TABLE 6: Pearson correlation (r) between serum and salivary cortisol concentrations in healthy volunteers and adrenal insufficient patients at different timepoints during the ACTH test.

\begin{tabular}{|c|c|c|c|c|c|c|c|c|c|}
\hline \multicolumn{6}{|c|}{$\mathrm{HV} \mathrm{SaC}$} & \multicolumn{4}{|c|}{$\mathrm{AI} \mathrm{SaC}$} \\
\hline & & $\mathrm{T}_{0}$ & $\mathrm{~T}_{30}$ & $\mathrm{~T}_{60}$ & $\mathrm{~T}_{90}$ & $\mathrm{~T}_{0}$ & $\mathrm{~T}_{30}$ & $\mathrm{~T}_{60}$ & $\mathrm{~T}_{90}$ \\
\hline \multirow{4}{*}{ HV TSC } & $\mathrm{T}_{0}$ & $0.83^{\mathrm{a}}$ & - & - & - & - & - & - & - \\
\hline & $\mathrm{T}_{30}$ & - & $0.67^{\mathrm{a}}$ & - & - & - & - & - & - \\
\hline & $\mathrm{T}_{60}$ & - & - & $0.54^{\mathrm{b}}$ & - & - & - & - & - \\
\hline & $\mathrm{T}_{90}$ & - & - & - & $0.62^{\mathrm{a}}$ & - & - & - & - \\
\hline \multirow{4}{*}{ AI TSC } & $\mathrm{T}_{0}$ & - & - & - & - & $0.14^{\mathrm{c}}$ & - & - & - \\
\hline & $\mathrm{T}_{30}$ & - & - & - & - & - & $0.49^{\mathrm{b}}$ & - & - \\
\hline & $\mathrm{T}_{60}$ & - & - & - & - & - & - & $0.71^{\mathrm{a}}$ & - \\
\hline & $\mathrm{T}_{90}$ & - & - & - & - & - & - & - & $0.79^{\mathrm{a}}$ \\
\hline
\end{tabular}

HV, healthy volunteers; AI, adrenal insufficiency; TSC, total serum cortisol; SaC, salivary cortisol; $\mathrm{T}_{0}$, baseline; $\mathrm{T}_{30}, 30$ min after administration; $\mathrm{T}_{60}, 60$ min after administration; $\mathrm{T}_{90}, 90 \mathrm{~min}$ after administration.

${ }^{\mathrm{a}} \mathrm{p}<0.0001,{ }^{\mathrm{b}} \mathrm{p}<0.01$, and ${ }^{\mathrm{c}} \mathrm{p}>0.05$.

TABLE 7: Number of cirrhotic patients meeting at least one criterion for the diagnosis of AI based on serum cortisol and salivary cortisol thresholds during $250 \mu \mathrm{g}$ ACTH test $(\mathrm{N}=39)$.

\begin{tabular}{|c|c|c|}
\hline Criterion & AI based on TSC & AI based on $\mathrm{SaC}$ \\
\hline AI defined from $\mathrm{T}_{0}, \mathrm{n}$ & $13^{\mathrm{a}}$ & $0^{\mathrm{d}}$ \\
\hline AI defined from $\mathrm{T}_{60}, \mathrm{n}$ & $9^{b}$ & $9^{e}$ \\
\hline AI defined from the difference between 0 and $60 \mathrm{~min}, \mathrm{n}$ & $10^{\mathrm{c}}$ & $12^{\mathrm{f}}$ \\
\hline $\begin{array}{l}\text { Total number of patients reaching at least one of the three criteria of adrenal } \\
\text { insufficiency, } \mathrm{n}(\%)\end{array}$ & $19(48.7 \%)$ & $12(30.8 \%)$ \\
\hline
\end{tabular}

$\mathrm{AI}$, adrenal insufficiency; TSC, total serum cortisol; $\mathrm{SaC}$, salivary cortisol; $\mathrm{T}_{0}$, baseline; $\mathrm{T}_{60}, 60$ min after administration. To convert cortisol micrograms per deciliter to nanomoles per liter, multiply by 27.6 .

${ }^{\mathrm{a}} \mathrm{T}_{0} \mathrm{TSC}<9 \mu \mathrm{g} / \mathrm{dL},{ }^{\mathrm{b}} \mathrm{T}_{60}$ TSC $<18 \mu \mathrm{g} / \mathrm{dL},{ }^{\mathrm{c}} \Delta \mathrm{TSC}<9 \mu \mathrm{g} / \mathrm{dL}$.

${ }^{\mathrm{d}} \mathrm{T}_{0} \mathrm{SaC}<0.08 \mu \mathrm{g} / \mathrm{dL},{ }^{\mathrm{e}} \mathrm{T}_{60} \mathrm{SaC}<1.43 \mu \mathrm{g} / \mathrm{dL},{ }^{\mathrm{f}} \Delta \mathrm{SaC}<1 \mu \mathrm{g} / \mathrm{dL}$.

Table 6 reports the correlations between $\mathrm{SaC}$ and TSC concentrations at different timepoints during the ACTH test. In $\mathrm{AI}$ patients, $\mathrm{SaC}$ and TSC correlated except at baseline, and the strength of the correlations increased over time. By contrast, in healthy patients, SaC and TSC correlated strongly at all timepoints.

3.2. Cirrhotic Subjects. Mean values of TSC and $\mathrm{SaC}$ at the different timepoints in the ACTH test in cirrhotic patients are reported in Tables 2 and 4, respectively; mean values of $\Delta \mathrm{TSC}$ and $\Delta \mathrm{SaC}$ are reported in Tables 3 and 5 , respectively. Based on the results for healthy subjects and AI patients, we selected the following cutoffs for the diagnosis of $\mathrm{AI}$ in cirrhotic patients $\mathrm{SaC}-\mathrm{T}_{0}<0.08 \mu \mathrm{g} / \mathrm{dL}(2.2 \mathrm{nmol} / \mathrm{L})$ or SaC$\mathrm{T}_{60}<1.43 \mu \mathrm{g} / \mathrm{dl}(39.5 \mathrm{nmol} / \mathrm{L})$ or $\Delta \mathrm{SaC}<1 \mu \mathrm{g} / \mathrm{dl}(27.6 \mathrm{nmol} / \mathrm{L})$.

Table 7 reports the numbers of cirrhotic patients that met each criterion for the diagnosis of AI with each method. Comparing the results of using the $\mathrm{SaC}$ thresholds versus the established TSC thresholds to diagnose AI in cirrhotic patients, we found 19 patients met at least one TSC criterion of $\mathrm{AI}$ and 12 patients met at least one $\mathrm{SaC}$ criterion; however, this difference in frequency did not reach statistical significance. The criteria for AI according to both of the two methods were met by $11(28.2 \%)$ patients; $8(20.5 \%)$ met only the TSC criteria, and 1 (2.6\%) met only the $\mathrm{SaC}$ criteria.
Based on these results, we classified cirrhotic patients into three groups: No AI ( $n=19)$, AI based on TSC and SaC criteria $(n=12)$, and AI based on TSC but not SaC criteria $(n=8)$. Comparing the characteristics of the patients in these groups, we found that the No-AI group had a higher proportion of women $\left(X^{2}=17.14 ; \mathrm{p}<0.001\right)$, more patients with non-alcoholrelated cirrhosis (although only 2 patients had non-alcoholrelated cirrhosis), and a greater-than-expected proportion of Child A and Child B patients $\left(X^{2}=20.10 ; p=0.0005\right)$; both AI groups had a greater-than-expected proportion of patients with alcohol-related cirrhosis $\left(X^{2}=25.29\right.$; $\left.p=0.0014\right)$. We found no significant differences between the three groups in age at diagnosis of cirrhosis, current MELD, blood albumin, prealbumin, HDL or LDL cholesterol, creatinine, triglycerides, AST, ALT, bilirubin, prothrombin time, INR, or reasons for admission.Cirrhotic subjects with AI diagnosed according to $\mathrm{SaC}$ levels were treated with glucocorticoid replacement therapy.

\section{Discussion}

To determine whether $\mathrm{SaC}$ can be used for diagnosing $\mathrm{AI}$ in noncritical cirrhotic patients, we established reference values for $\mathrm{SaC}$ at $\mathrm{T}_{0}$ and $\mathrm{T}_{60}$ and for $\Delta \mathrm{SaC}\left(\mathrm{T}_{0}-\mathrm{T}_{60}\right)$ based on $\mathrm{SaC}$ and TSC findings in normal subjects and patients with known AI. 
We found that $\mathrm{SaC}$ can be very useful for diagnosis of $\mathrm{AI}$ in cirrhotic patients.

Determining $\mathrm{SaC}$ is a quick, easy, noninvasive technique used since the early 1980s, when $\mathrm{SaC}$ was discovered to be an excellent indicator of plasma FC concentration [21, 22]. Various authors have since studied TSC and SaC in different circumstances in which cortisol-binding globulin is altered (oral contraception, pregnancy, and cirrhosis) [10, 23]. In 2009, Deutschbein et al. [23] compared basal SaC and basal TSC to the insulin tolerance test in 77 patients with hypothalamic-pituitary disease, concluding that both approaches enabled a highly specific diagnosis, obviating insulin tolerance testing in about one-fourth of cases. In 2012, they found basal $\mathrm{SaC}<0.11 \mu \mathrm{g} / \mathrm{dL}(3.0 \mathrm{nmol} / \mathrm{L})$ had 97\% specificity and $40 \%$ sensitivity for AI, enabling correct classification in 26\% [24]. By contrast, Ceccato et al. [25] concluded that unstimulated $\mathrm{SaC}<0.09 \mu \mathrm{g} / \mathrm{dL}(2.5 \mathrm{nmol} / \mathrm{L})$ distinguished AI patients from healthy subjects with $97.1 \%$ sensitivity and $93.3 \%$ specificity. Recently, Langelaan et al. [26] recommended a new diagnostic algorithm to diagnose AI, with early morning $\mathrm{SaC}>0.21 \mu \mathrm{g} / \mathrm{dL}(5.8 \mathrm{nmol} / \mathrm{L})$ ruling out $\mathrm{AI}$ and $<0.04 \mu \mathrm{g} / \mathrm{dL}(1.1 \mathrm{nmol} / \mathrm{L})$ diagnosing AI; these cutoffs enabled $34 \%$ of patients to be diagnosed without ACTH stimulation. In our study, $\mathrm{SaC}_{-} \mathrm{T}_{0}<0.08 \mu \mathrm{g} / \mathrm{dL}(2.2 \mathrm{nmol} / \mathrm{L})$ (the lowest $\mathrm{SaC}-\mathrm{T}_{0}$ value in normal subjects) diagnosed 7.7\% of patients with AI; the differences in cutoffs might be due to differences in laboratory methods for determining $\mathrm{SaC}$.

In 1988, Laudat et al. [27] found no overlap in $\mathrm{SaC} \mathrm{T}_{60}$ after $250 \mu \mathrm{g}$ ACTH between 58 healthy volunteers and 21 subjects with $\mathrm{AI}$; discrepancies between $\mathrm{SaC}$ and TSC in 8 patients with AI were attributed to thyroid hormones and psychotropic agents. Various studies have since examined correlations between TSC and SaC during $1 \mu \mathrm{g}$ or $250 \mu \mathrm{g}$ ACTH tests [16, 28-30]. Correlations between TSC and SaC are good; the issue is choosing the optimal $\mathrm{SaC}$ cutoff for AI. Methodological differences among studies make comparisons difficult. Some studies included healthy volunteers and patients with known AI, whereas others included subjects with suspected AI. Moreover, some used $1 \mu \mathrm{g} \mathrm{ACTH,}$ whereas others used $250 \mu \mathrm{g}$. Finally, different studies used different methods to measure $\mathrm{SaC}$ and TSC, and the normal response to ACTH tests is assay-specific [31]. Thus, despite the available data, clinicians face uncertainty in choosing cutoffs.

We compared $\mathrm{SaC}$ and TSC before and after administering $250 \mu \mathrm{g}$ ACTH in healthy subjects and patients with known AI to calculate reference values for basal $\mathrm{SaC}$, peak $\mathrm{SaC}$ at $\mathrm{T}_{60}$, and $\Delta \mathrm{SaC}\left(\mathrm{T}_{0}-\mathrm{T}_{60}\right)$. We used these references to determine the prevalence of $\mathrm{AI}$ in a cohort of decompensated cirrhotic patients and compared the results with those found using established TSC cutoffs. Whereas the established TSC cutoffs classified $48.7 \%$ of the cirrhotic patients as AI, our $\mathrm{SaC}$ cutoffs classified only $30.8 \%$ as AI. The difference was not statistically significant, probably due to the low number of cirrhotic patients, but it shows a clear tendency. At least one $\mathrm{SaC}$ criterion and one TSC criterion for AI were met in 11 (28.2\%); 8 (20.5\%) had AI according to TSC but not according to $\mathrm{SaC}$, and 1 patient had $\mathrm{AI}$ according to $\mathrm{SaC}$ but not TSC.
The $30.8 \%$ SaC-determined prevalence in our noncritical cirrhotic patients is higher than the $9.1 \%$ found by Galbois et al. [32]; it is also higher than the $19 \%$ prevalence calculated by Fede et al. [33] by measuring FC after a $1 \mu \mathrm{g}$ ACTH test. As in other studies, we found that TSC overestimated the prevalence of AI (48.7\% in our study, 33\% in Galbois et al. [32], and 34\% in Fede et al. [33]). The higher prevalence of $\mathrm{AI}$ in our study might be due to greater liver disease severity ( $85 \%$ Child B or C); we found that severity was associated with a higher risk of AI. We also found that sex and cirrhosis etiology were associated with AI frequency.

Several studies identified ascites, low HDL-cholesterol, and liver disease severity as risk factors for AI [32, 34-36]; other reported risk factors include low cortisol-binding globulin [33], higher MELD score [37], and lower serum albumin [32]. Galbois et al. [32] reported that hypoalbuminemia was the main reason for discrepancies between TSC and $\mathrm{SaC}$ assessments of AI, suggesting that a lower threshold of 25 $\mathrm{g} / \mathrm{L}$ could be used to identify patients who could benefit from a $\mathrm{SaC}$ assessment. When we analyzed the subgroup of patients with albumin $<25 \mathrm{~g} / \mathrm{L}$, we found no differences in the prevalence of AI measured by $\mathrm{SaC}$ or TSC, probably because few (8/39) patients had albumin $<25 \mathrm{~g} / \mathrm{L}$.

Our study has several limitations. We calculated diseasespecific thresholds of $\mathrm{SaC}$ measured by electrochemiluminescence immunoassay, the method routinely used in our hospital. Liquid chromatography tandem-mass spectrometry is more specific but requires expensive equipment [38]. Despite the risk of overestimating $\mathrm{SaC}$, potential crossreactivity with other steroids, and different results obtained with different types of analyzers $[39,40]$, we consider the use of electrochemiluminescence immunoassay justified because it is the method most commonly used in clinical practice. Moreover, we did not measure FC, because doing so is complex, expensive, and uncommon in clinical practice; likewise, we did not measure cortisol-binding globulin, so we could not calculate FC with Coolens' equation.

In diagnostic accuracy studies, how eligible subjects are identified and recruited is important. We included only hemodynamically stable cirrhotic patients, so our findings cannot be extrapolated to cirrhotic patients with sepsis or septic shock. On the other hand, we determined cutoffs from our findings in patients with known AI and healthy volunteers with low probability of AI, adding strength to our results. Other studies derived cutoffs from findings in patients with suspected AI, and that design could influence the spectrum of disease in included patients [41]. Moreover, test sensitivity is usually higher in studies with patients with more advanced stages of the target condition [42].

Measuring $\mathrm{SaC}$ has some methodological limitations. SaC's concentration is 30 -fold lower than TSC's. Additionally, $\mathrm{SaC}$ levels are affected by salivary $11 \beta$-hydroxysteroid dehydrogenase type 2. In 2010, Perogamvros et al. [43] suggested using salivary cortisone better reflects FC after adrenal stimulation. Cornes et al. [40] report that concentrations of salivary cortisone are three times higher than those of $\mathrm{SaC}$ and have a closer linear correlation with serum FC. Debono et al. [44] also suggested that salivary cortisone may be the preferred analyte for noninvasive measurement of FC. 


\section{Conclusions}

We establish method-specific reference cutoffs of $\mathrm{SaC}$ and $\Delta \mathrm{SaC}$ to determine AI during the $250 \mu \mathrm{g}$ ACTH stimulation test. $\mathrm{SaC}$ is more accurate than TSC for assessing adrenal function with the $250 \mu \mathrm{g}$ ACTH stimulation test in noncritical cirrhotic patients. The prevalence AI in our cirrhotic group was higher than in other studies. However, it should be taken into account that we did not measure CBG levels. Further studies with more cases are necessary to establish $\mathrm{SaC}$ reference values to correctly classify patients with $\mathrm{AI}$ and avoid unnecessary cortisol replacement treatment.

\section{Data Availability}

The data used to support the findings of this study are available from the corresponding author upon request.

\section{Ethical Approval}

Our institution's ethics committee approved this prospective study.

\section{Consent}

All subjects provided written informed consent.

\section{Disclosure}

An earlier version of the study has been presented as a poster in Cirrhosis: Clinical aspects. https://www.sciencedirect.com/ science/article/abs/pii/S0168827816003056.

\section{Conflicts of Interest}

The authors have no conflicts of interest regarding this study.

\section{Authors' Contributions}

Lara Albert and Joaquím Profitós contributed equally to this work.

\section{Acknowledgments}

This study was financed by a grant from Fundació Parc Taulí: CIR [2012/22].

\section{References}

[1] J. O’Beirne, M. Holmes, B. Agarwal et al., "Adrenal insufficiency in liver disease - What is the evidence?" Journal of Hepatology, vol. 47, no. 3, pp. 418-423, 2007.

[2] M.-H. Tsai, Y.-S. Peng, and Y.-C. Chen, "Adrenal insufficiency in patients with cirrhosis, severe sepsis and septic shock," Hepatology, vol. 43, no. 4, pp. 673-681, 2006.
[3] B. Zietz, G. Lock, B. Plach et al., "Dysfunction of the hypothalamic-pituitary-glandular axes and relation to ChildPugh classification in male patients with alcoholic and virusrelated cirrhosis," European Journal of Gastroenterology \& Hepatology, vol. 15, no. 5, pp. 495-501, 2003.

[4] S. R. Bornstein, B. Allolio, W. Arlt et al., "Diagnosis and treatment of primary adrenal insufficiency: An endocrine society clinical practice guideline," The Journal of Clinical Endocrinology \& Metabolism, vol. 101, no. 2, pp. 364-389, 2016.

[5] R. Kazlauskaite, A. T. Evans, C. V. Villabona et al., "Corticotropin tests for hypothalamic-pituitary-adrenal insufficiency: A metaanalysis," The Journal of Clinical Endocrinology \& Metabolism, vol. 93, no. 11, pp. 4245-4253, 2008.

[6] W. Rosner, "The functions of corticosteroid-binding globulin and sex hormone-binding globulin: Recent advances," Endocrine Reviews, vol. 11, no. 1, pp. 80-91, 1990.

[7] J. D. Baxter and P. H. Forsham, "Tissue effects of glucocorticoids," American Journal of Medicine, vol. 53, no. 5, pp. 573-589, 1972.

[8] J. F. Dunn, B. C. Nisula, and D. Rodbard, "Transport of steroid hormones: binding of 21 endogenous steroids to both testosterone-binding globulin and corticosteroid-binding globulin in human plasma," The Journal of Clinical Endocrinology \& Metabolism, vol. 53, no. 1, pp. 58-68, 1981.

[9] R. P. Vincent, F. E. Etogo-Asse, T. Dew, W. Bernal, J. Alaghband-Zadeh, and C. W. Le Roux, "Serum total cortisol and free cortisol index give different information regarding the hypothalamus-pituitary-adrenal axis reserve in patients with liver impairment," Annals of Clinical Biochemistry, vol. 46, no. 6, pp. 505-507, 2009.

[10] D. Suri, J. Moran, J. U. Hibbard, K. Kasza, and R. E. Weiss, "Assessment of adrenal reserve in pregnancy: defining the normal response to the adrenocorticotropin stimulation test," The Journal of Clinical Endocrinology \& Metabolism, vol. 91, no. 10, pp. 3866-3872, 2006.

[11] H. Raff, S. Brock, and J. W. Findling, "Cosyntropin-stimulated salivary cortisol in hospitalized patients with hypoproteinemia," Endocrine Journal, vol. 34, no. 1-3, pp. 68-74, 2008.

[12] M. Rauschecker, S. B. Abraham, B. S. Abel et al., "Cosyntropinstimulated serum free cortisol in healthy, adrenally insufficient, and mildly cirrhotic populations," The Journal of Clinical Endocrinology \& Metabolism, vol. 101, no. 3, pp. 1075-1081, 2016.

[13] N. Molenaar, A. B. J. Groeneveld, and M. F. C. de Jong, “Three calculations of free cortisol versus measured values in the critically ill," Clinical Biochemistry, vol. 48, no. 16-17, pp. 10531058,2015

[14] B. M. Arafah, F. J. Nishiyama, H. Tlaygeh, and R. Hejal, "Measurement of salivary cortisol concentration in the assessment of adrenal function in critically ill subjects: A surrogate marker of the circulating free cortisol," The Journal of Clinical Endocrinology \& Metabolism, vol. 92, no. 8, pp. 2965-2971, 2007.

[15] H. Raff, "Utility of salivary cortisol measurements in Cushing's syndrome and adrenal insufficiency," The Journal of Clinical Endocrinology \& Metabolism, vol. 94, no. 10, pp. 3647-3655, 2009.

[16] J. G. Lewis, "Steroid analysis in saliva: an overview," The Clinical Biochemist Reviews, vol. 27, no. 3, pp. 139-146, 2006.

[17] P. E. Marik, S. M. Pastores, D. Annane et al., "Recommendations for the diagnosis and management of corticosteroid insufficiency in critically ill adult patients: consensus statements from an international task force by the American College of Critical 
Care Medicine," Critical Care Medicine, vol. 36, no. 6, pp. 19371949, 2008.

[18] R. I. Dorin, C. R. Qualls, and L. M. Crapo, "Diagnosis of adrenal insufficiency," Annals of Internal Medicine, vol. 139, no. 3, pp. 194-204, 2003.

[19] I. Lopez Schmidt, H. Lahner, K. Mann, and S. Petersenn, "Diagnosis of adrenal insufficiency: Evaluation of the corticotropinreleasing hormone test and basal serum cortisol in comparison to the insulin tolerance test in patients with hypothalamicpituitary-adrenal disease," The Journal of Clinical Endocrinology \& Metabolism, vol. 88, no. 9, pp. 4193-4198, 2003.

[20] R. F. Vining, R. A. McGinley, J. J. Maksvytis, and K. Y. Ho, "Salivary cortisol: a better measure of adrenal cortical function than serum cortisol," Annals of Clinical Biochemistry, vol. 20, part 6, pp. 329-335, 1983.

[21] U. Teruhisa, H. Ryoji, I. Taisuke, S. Tatsuya, M. Fumihiro, and S. Tatsuo, "Use of saliva for monitoring unbound free cortisol levels in serum," Clinica Chimica Acta, vol. 110, no. 2-3, pp. 245253, 1981.

[22] B. J. Nolan, J. Sorbello, N. Brown, G. Dimeski, and W. J. Inder, "Characterization of the serum and salivary cortisol response to the intravenous $250 \mu \mathrm{g}$ ACTH1-24 stimulation test," Endocrine Journal, vol. 59, no. 3, pp. 520-528, 2018.

[23] T. Deutschbein, N. Unger, K. Mann, and S. Petersenn, “Diagnosis of secondary adrenal insufficiency: Unstimulated early morning cortisol in saliva and serum in comparison with the insulin tolerance test," Hormone and Metabolic Research, vol. 41, no. 11, pp. 834-839, 2009.

[24] T. Deutschbein, M. Broecker-Preuss, J. Flitsch et al., "Salivary cortisol as a diagnostic tool for Cushing's syndrome and adrenal insufficiency: Improved screening by an automatic immunoassay," European Journal of Endocrinology, vol. 166, no. 4, pp. 613618, 2012.

[25] F. Ceccato, M. Barbot, M. Zilio et al., "Performance of salivary cortisol in the diagnosis of Cushing's syndrome, adrenal incidentaloma, and adrenal insufficiency," European Journal of Endocrinology, vol. 169, no. 1, pp. 31-36, 2013.

[26] M. L. P. Langelaan, J. M. H. Kisters, M. M. Oosterwerff, and A.-K. Boer, "Salivary cortisol in the diagnosis of adrenal insufficiency: Cost efficient and patient friendly," Endocrine Connections, vol. 7, no. 4, pp. 560-566, 2018.

[27] M. H. Laudat, S. Cerdas, C. Fournier, D. Guiban, B. Guilhaume, and J. P. Luton, "Salivary cortisol measurement: A practical approach to assess pituitary-adrenal function," The Journal of Clinical Endocrinology \& Metabolism, vol. 66, no. 2, pp. 343348, 1988.

[28] Y. Marcus-Perlman, K. Tordjman, Y. Greenman et al., "Lowdose ACTH $(1 \mu \mathrm{g})$ salivary test: A potential alternative to the classical blood test," Clinical Endocrinology, vol. 64, no. 2, pp. 215-218, 2006.

[29] T. Deutschbein, N. Unger, K. Mann, and S. Petersenn, "Diagnosis of secondary adrenal insufficiency in patients with hypothalamic-pituitary disease: Comparison between serum and salivary cortisol during the high-dose short synacthen test," European Journal of Endocrinology, vol. 160, no. 1, pp. 9-16, 2009.

[30] I. Perogamvros, L. J. Owen, B. G. Keevil, G. Brabant, and P. J. Trainer, "Measurement of salivary cortisol with liquid chromatography-tandem mass spectrometry in patients undergoing dynamic endocrine testing," Clinical Endocrinology, vol. 72, no. 1, pp. 17-21, 2010.
[31] M. C. Klose, M. Lange, A. K. Rasmussen et al., "Factors influencing the adrenocorticotropin test: Role of contemporary cortisol assays, body composition, and oral contraceptive agents," The Journal of Clinical Endocrinology \& Metabolism, vol. 92, no. 4, pp. 1326-1333, 2007.

[32] A. Galbois, M. Rudler, J. Massard et al., "Assessment of adrenal function in cirrhotic patients: Salivary cortisol should be preferred," Journal of Hepatology, vol. 52, no. 6, pp. 839-845, 2010.

[33] G. Fede, L. Spadaro, T. Tomaselli et al., "Comparison of total cortisol, free cortisol, and surrogate markers of free cortisol in diagnosis of adrenal insufficiency in patients with stable cirrhosis," Clinical Gastroenterology and Hepatology, vol. 12, no. 3, pp. 504-e8, 2014.

[34] P. E. Marik, T. Gayowski, and T. E. Starzl, "The hepatoadrenal syndrome: a common yet unrecognized clinical condition," Critical Care Medicine, vol. 33, no. 6, pp. 1254-1259, 2005.

[35] P. E. Marik, "Adrenal-exhaustion syndrome in patients with liver disease," Intensive Care Medicine, vol. 32, no. 2, pp. 275280, 2006.

[36] P. H. J. Van Der Voort, R. T. Gerritsen, A. J. Bakker, E. C. Boerma, M. A. Kuiper, and L. De Heide, "HDL-cholesterol level and cortisol response to synacthen in critically ill patients," Intensive Care Medicine, vol. 29, no. 12, pp. 2199-2203, 2003.

[37] T. Thevenot, S. Borot, A. Remy-Martin et al., "Assessment of adrenal function in cirrhotic patients using concentration of serum-free and salivary cortisol," Liver International, vol. 31, no. 3, pp. 425-433, 2011.

[38] A. E. Taylor, B. Keevil, and I. T. Huhtaniemi, "Mass spectrometry and immunoassay: How to measure steroid hormones today and tomorrow," European Journal of Endocrinology, vol. 173, no. 2, pp. D1-D12, 2015.

[39] M. Dušková, K. Šimůnková, J. Vítků et al., "A comparison of salivary steroid levels during diagnostic tests for adrenal insufficiency," Prague Medical Report, vol. 117, no. 1, pp. 18-33, 2016.

[40] M. P. Cornes, H. L. Ashby, Y. Khalid, H. N. Buch, C. Ford, and R. Gama, "Salivary cortisol and cortisone responses to tetracosactrin (synacthen)," Annals of Clinical Biochemistry, vol. 52, no. 5, pp. 606-610, 2015.

[41] P. M. Bossuyt, J. B. Reitsma, D. E. Bruns et al., "STARD 2015: An updated list of essential items for reporting diagnostic accuracy studies," BMJ, vol. 351, p. h5527, 2015.

[42] D. F. Ransohoff and A. R. Feinstein, "Problems of spectrum and bias in evaluating the efficacy of diagnostic tests," The New England Journal of Medicine, vol. 299, no. 17, pp. 926-930, 1978.

[43] I. Perogamvros, B. G. Keevil, D. W. Ray, and P. J. Trainer, "Salivary cortisone is a potential biomarker for serum free cortisol," The Journal of Clinical Endocrinology \& Metabolism, vol. 95, no. 11, pp. 4951-4958, 2010.

[44] M. Debono, R. F. Harrison, M. J. Whitaker et al., "Salivary cortisone reflects cortisol exposure under physiological conditions and after hydrocortisone," The Journal of Clinical Endocrinology \& Metabolism, vol. 101, no. 4, pp. 1469-1477, 2016. 


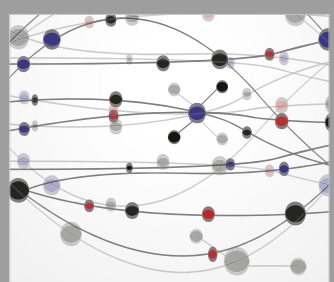

The Scientific World Journal
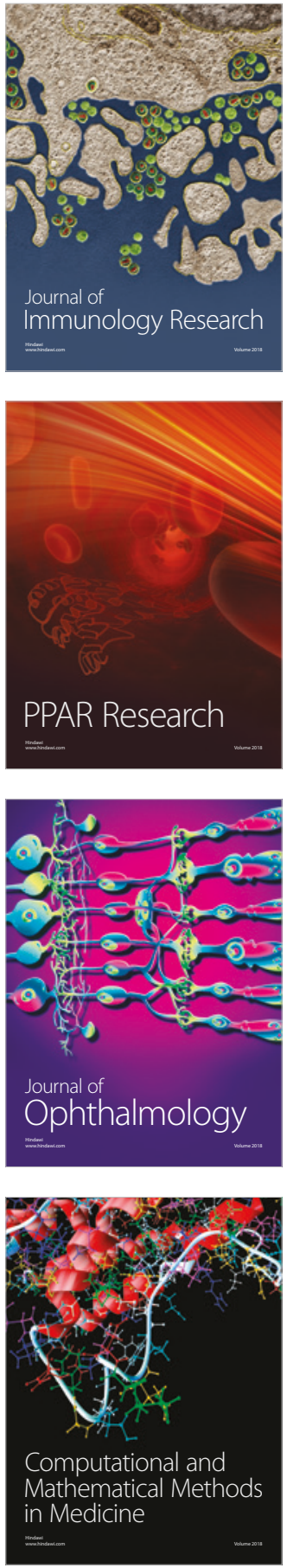

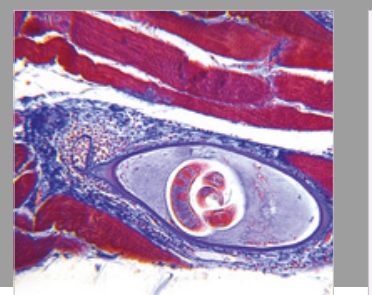

Gastroenterology Research and Practice

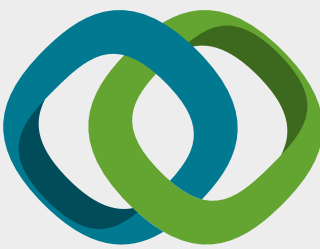

\section{Hindawi}

Submit your manuscripts at

www.hindawi.com
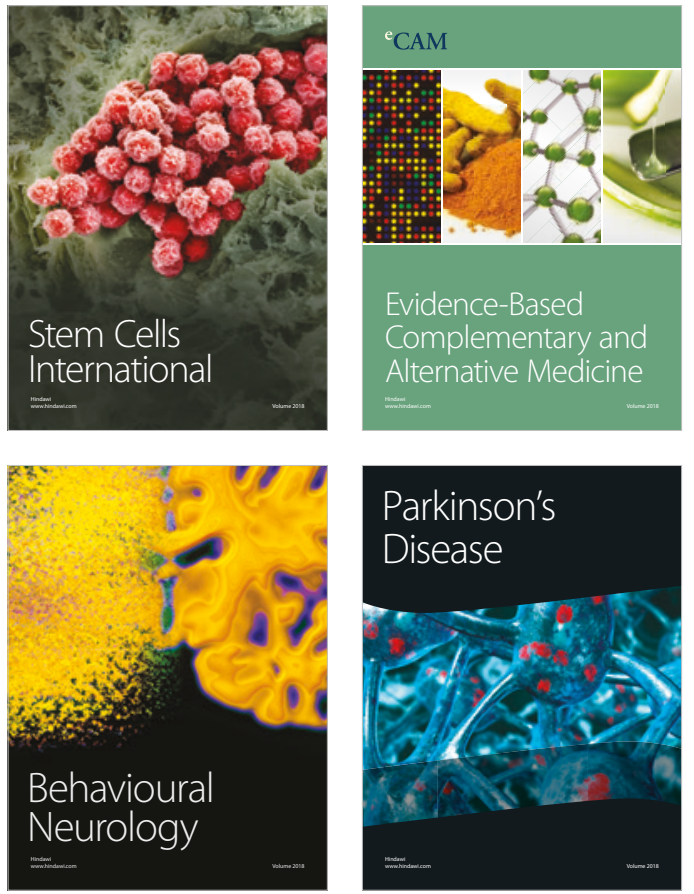

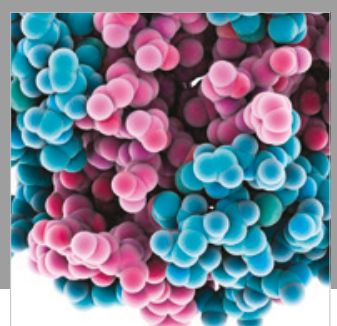

ournal of

Diabetes Research

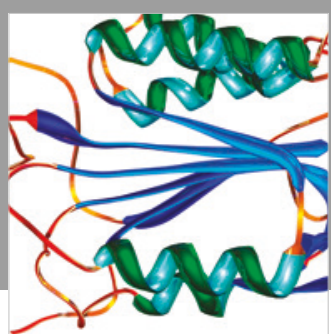

Disease Markers
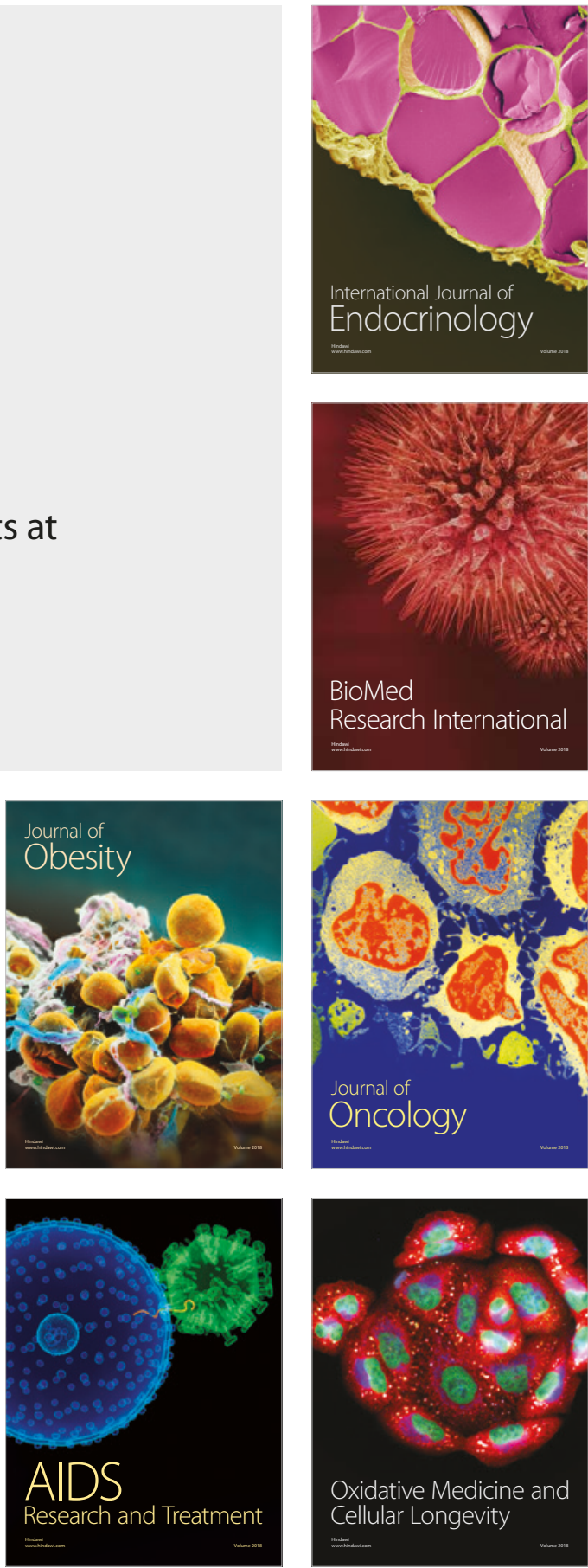